\title{
Inhibition of Elevated Ras-MAPK Signaling Normalizes Enhanced Motor Learning and Excessive Clustered Dendritic Spine Stabilization in the MECP2-Duplication Syndrome Mouse Model of Autism
}

\author{
Ryan Thomas Ash, , 1,2,3,4 Shelly Alexandra Buffington, ${ }^{5,6}$ Jiyoung Park, ${ }^{2,4}$ Bernhard Suter, ${ }^{4,7}$ \\ Mauro Costa-Mattioli, ${ }^{2,5}$ Huda Yaya Zoghbi, ${ }^{2,7,8,9,10}$ and ${ }^{-S t e l i o s ~ M a n o l i s ~ S m i r n a k i s ~}{ }^{4}$
}

https://doi.org/10.1523/ENEURO.0056-21.2021

${ }^{1}$ Department of Psychiatry and Behavioral Sciences, Stanford University, CA 94305, ${ }^{2}$ Department of Neuroscience, Baylor College of Medicine, Houston, TX 77030, ${ }^{3}$ Medical Scientist Training Program, Baylor College of Medicine, Houston, TX 77030, ${ }^{4}$ Department of Neurology, Brigham and Women's Hospital and Jamaica Plain Veterans Administration Hospital, Harvard Medical School, Boston, MA 02115, ${ }^{5}$ Memory and Brain Research Center, Baylor College of Medicine, Houston, TX 77030, ${ }^{6}$ Department of Neuroscience, Cell Biology, and Anatomy, University of Texas Medical Branch, Galveston, TX 77555, ${ }^{7}$ Department of Pediatrics, Texas Children's Hospital and Baylor College of Medicine, Houston, TX 77030, ${ }^{8}$ Department of Molecular and Human Genetics, Baylor College of Medicine, Houston, TX 77030, ${ }^{9} \mathrm{Jan}$ and Dan Duncan Neurological Research Institute at Texas Children's Hospital, Houston, TX 77030, and ${ }^{10}$ Howard Hughes Medical Institute, Baylor College of Medicine, Houston, TX 77030

\section{Visual Abstract}
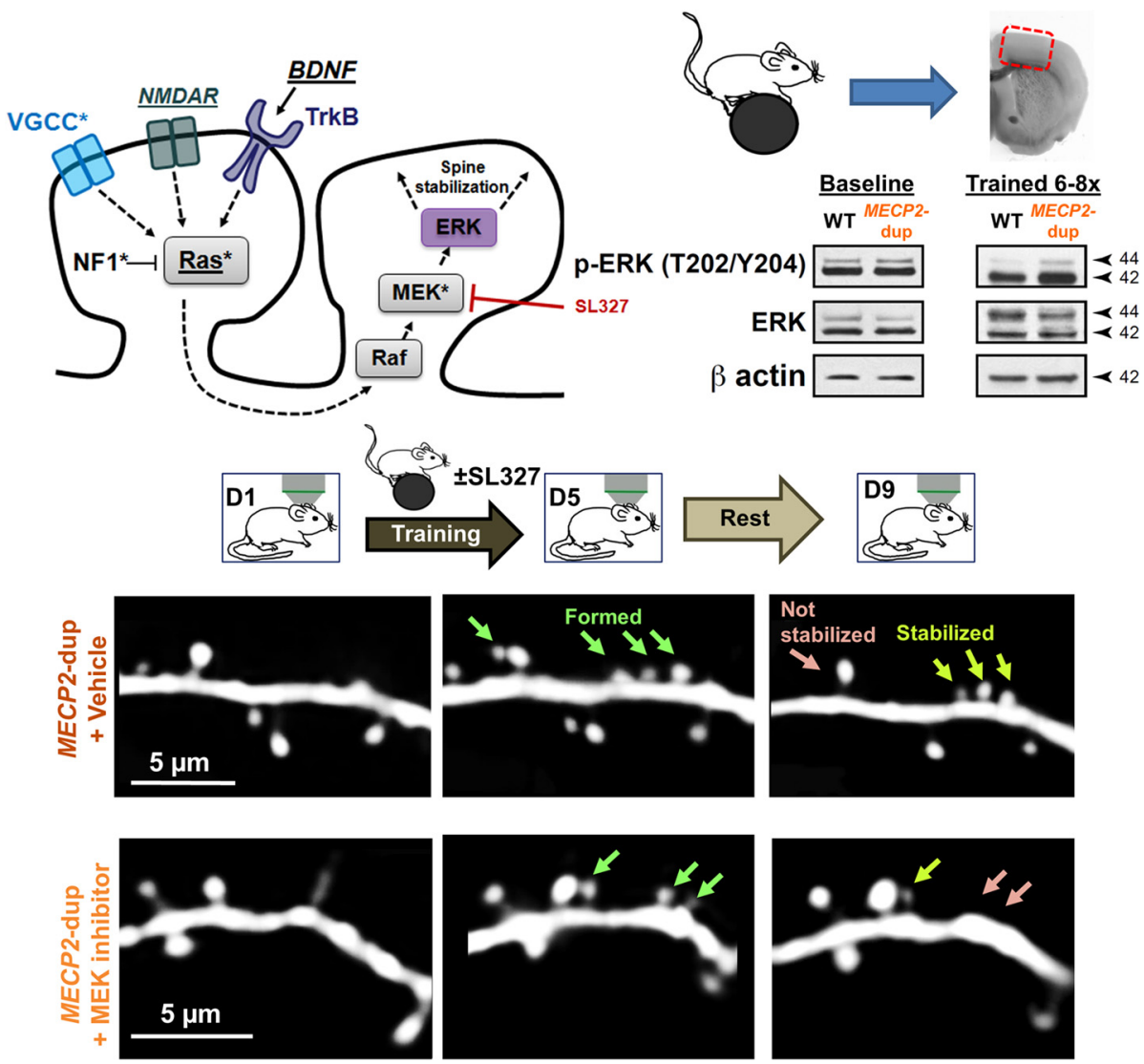


\section{Significance Statement}

It has been proposed that autism-associated genetic mutations lead to altered learning phenotypes by perturbing cell signaling pathways that regulate synaptic plasticity in the brain. The Ras-ERK/MAPK signaling pathway, which promotes stabilization of dendritic spine clusters, has been particularly implicated in autism spectrum disorder (ASD). Here, we show that Ras-ERK signaling is increased in motor cortex following rotarod training in the MECP2-duplication syndrome mouse model of autism, and that the abnormal motor learning and excessive stabilization of clustered dendritic spines previously observed in MECP2-duplication mice can be rescued by pharmacological inhibition of Ras-ERK signaling. This provides additional support to hypotheses that autistic phenotypes arise from disrupted Ras-ERK signaling and synaptic plasticity and suggest potential future paths for therapeutic intervention.

\section{Abstract}

The inflexible repetitive behaviors and "insistence on sameness" seen in autism imply a defect in neural processes controlling the balance between stability and plasticity of synaptic connections in the brain. It has been proposed that abnormalities in the Ras-ERK/MAPK pathway, a key plasticity-related cell signaling pathway known to drive consolidation of clustered synaptic connections, underlie altered learning phenotypes in autism. However, a link between altered Ras-ERK signaling and clustered dendritic spine plasticity has yet to be explored in an autism animal model in vivo. The formation and stabilization of dendritic spine clusters is abnormally increased in the MECP2-duplication syndrome mouse model of syndromic autism, suggesting that ERK signaling may be increased. Here, we show that the Ras-ERK pathway is indeed hyperactive following motor training in MECP2-duplication mouse motor cortex. Pharmacological inhibition of ERK signaling normalizes the excessive clustered spine stabilization and enhanced motor learning behavior in MECP2-duplication mice. We conclude that hyperactive ERK signaling may contribute to abnormal clustered dendritic spine consolidation and motor learning in this model of syndromic autism.

Key words: autism; dendritic spine; ERK; MAPK; MECP2; spine clustering

\section{Introduction}

It has been proposed that phenotypes of autism spectrum disorder (ASD) arise from an abnormal imbalance

Received February 9, 2021; accepted April 7, 2021; First published May 21, 2021.

The authors declare no competing financial interests.

Author contributions: R.T.A., S.A.B., B.S., M.C.-M., H.Y.Z., and S.M.S. designed research; R.T.A., S.A.B., J.P., and B.S. performed research; R.T.A., S.A.B., J.P., M.C.-M., H.Y.Z., and S.M.S. contributed unpublished reagents/ analytic tools; R.T.A. and S.A.B. analyzed data; R.T.A. and S.M.S. wrote the paper.

R.T.A. was supported by the Autism Speaks Weatherstone Fellowship and the Baylor College of Medicine Medical Scientist Training Program. This work was supported by Simons Foundation Grants 240069 and 402047 and March of Dimes (to S.M.S.), the Howard Hughes Medical Institute and National Institute of Neurological Disorders and Stroke Grant HD053862 (to H.Y.Z.), and the Baylor Intellectual and Developmental Disabilities Research Center Grant P50HD103555 Mouse Neurobehavioral Core.

Acknowledgements: We thank G. Allen, S. Torsky, E. Sztainberg, B. Suter, J. Meyer, A. Palagina, J. Patterson, S. Shen, D. Yu, and K. Tolias for technical and theoretical advice on experiments and comments on this manuscript. We also thank $\mathrm{H}$. Lu for the images of mouse coronal brain slices.

Correspondence should be addressed to Stelios Manolis Smirnakis at smsmirnakis@bwh.harvard.edu.

https://doi.org/10.1523/ENEURO.0056-21.2021

Copyright (C) 2021 Ash et al.

This is an open-access article distributed under the terms of the Creative Commons Attribution 4.0 International license, which permits unrestricted use, distribution and reproduction in any medium provided that the original work is properly attributed. between the stability and plasticity of synaptic connections in the brain (Ramocki and Zoghbi, 2008). Syndromic autism refers to a subgroup of ASD caused by genetic abnormalities that cause autism at high penetrance (Sztainberg and Zoghbi, 2016). Modeling these genetic abnormalities in mice has led to the development of autism animal models with improved validity (Sztainberg and Zoghbi, 2016). Abnormal synaptic plasticity is a common feature in animal models of autism (Bourgeron, 2015). Some autism mouse models exhibit impaired synaptic plasticity whereas others show enhanced synaptic plasticity (Bourgeron, 2015). Understanding the molecular mechanisms underlying these plasticity changes could open new avenues for therapeutic intervention. Animal models for the methylCpG-binding-protein 2 (MeCP2) disorders Rett syndrome (MeCP2 loss-of-function) and MECP2-duplication syndrome (MeCP2 gain-of-function) in particular have led to a wealth of findings on the molecular biological and neural circuit underpinnings of ASD (Collins et al., 2004; Jiang et al., 2013; Lyst and Bird, 2015; Lu et al., 2016; Sztainberg and Zoghbi, 2016) and identified potential avenues for treatment (Na et al., 2014; Hao et al., 2015; Sztainberg et al., 2015; Achilly et al., 2021).

Enhanced repetitive motor learning on the rotarod is observed in several autism mouse models with prominent behavioral inflexibility, including MECP2-duplication (Collins et al., 2004; Sztainberg et al., 2015), neuroligin-3 
(Rothwell et al., 2014), 15q duplication (Nakatani et al., 2009), PTEN (Kwon et al., 2006), and CNTNAP2 mice (Peñagarikano et al., 2011), providing a robust model behavior for studying the abnormal consolidation of repetitive motor routines. It was previously reported that an aberrant increase in the formation and stabilization of dendritic spine clusters in the animal model of MECP2duplication syndrome correlated with an enhancement in motor performance on the rotarod task (Ash et al., 2021). The increased clustered-spine stability in the $\sim 9$ - to 10$\mu \mathrm{m}$ proximity range that was observed is strikingly similar to the range of a known BDNF-TrkB-Ras-ERK-dependent form of clustered-spine plasticity (Harvey and Svoboda, 2007; Harvey et al., 2008; Makino and Malinow, 2011; Niculescu et al., 2018). Ras-ERK/MAPK signaling in hippocampal pyramidal neurons has been shown in vitro to be involved in the cooperative potentiation of neighboring dendritic spines (Harvey et al., 2008; Patterson et al., 2010; Kwon and Sabatini, 2011). When a spine is activated, Ras enters its GTP-bound active state and diffuses 9-10 $\mu \mathrm{m}$ down the dendrite to invade neighboring spines. There it initiates the ERK phosphorylation cascade orchestrating a number of transcriptional and translational changes associated with synaptic consolidation ( $\mathrm{Ye}$ and Carew, 2010).

Mutations in Ras-MAPK pathway genes are linked to several forms of autism (Stornetta and Zhu, 2011; Wen et al., 2016; Vithayathil et al., 2018), and both patients and animal models of autism demonstrate abnormal Ras-MAPK signaling (Ebert and Greenberg, 2013; Cheng et al., 2017; Rosina et al., 2019). Ras-MAPK genes have also been shown to be dysregulated in MECP2-duplication mice (Chahrour et al., 2008). We therefore hypothesized that hyperactive ERK signaling could contribute to the abnormal plasticity phenotypes observed in our animals.

Here, we show that Ras-ERK signaling is upregulated in the motor cortex of MECP2-duplication animals after motor training, and both excessive synaptic clustering and enhanced motor learning can be reversed by pharmacological normalization of ERK signaling. These data link a structural dendritic spine phenotype to a specific autism-associated cell-signaling pathway in a mouse model of autism, in vivo.

\section{Materials and Methods}

\section{Animals}

FVB-background MECP2-duplication (Tg1) mice (Collins et al., 2004), were crossed to C57 thy1-GFP-M homozygotes obtained from The Jackson Laboratory, to generate F1C57;FVB MECP2-duplication;thy1-GFP$M$ mice and thy1-GFP-M littermate controls. Males and females were used in experiments. Animals were housed in a 12/12 h light/dark cycle (lights on from $7 \mathrm{~A}$. M. to 7 P.M.). All experiments with animals were conducted in accordance with the National Institutes of Health guidelines for the care and use of laboratory animals and were approved by the institution's Institutional Animal Care and Use Committee.

\section{Blinding}

In data reported in Figure 1, mice from each genotype were randomly assigned to the drug or vehicle condition. Material to be injected was placed into individual tubes for each animal, then mice were injected without knowledge of the test tube's contents. Mice were trained, motor cortex was harvested, and Westerns were run and analyzed blind to condition. In Figure 2 data, imaging, rotarod training, drug/vehicle injection, and data analysis were performed blinded to experimental condition.

\section{In vivo two-photon imaging}

Experiments were performed as in Ash et al. (2021). At least two weeks before the first imaging session ( $12-$ to 14-week-old mice), a 3-mm-wide opening was drilled over motor cortex, centered at $1.6 \mathrm{~mm}$ lateral to bregma based on (Tennant et al., 2011), and a glass coverslip was placed over the exposed brain surface to allow chronic imaging of neuronal morphology (Mostany and PorteraCailliau, 2008, 2011). Dendritic spines were imaged using a Zeiss in vivo two-photon microscope with Zeiss $20 \times 1.0$ NA water-immersion objective lens. High-quality craniotomies had a characteristic bright-field appearance with well-defined vasculature and pale gray matter. Under two-photon scanning fluorescent dendrites were reliably clear and visible with low laser power $(<20 \mathrm{~mW}$ on the pia) and photomultiplier tube voltage.

Only high-quality preparations (low background noise across all time points, $<5$-pixel $(0.25 \mu \mathrm{m})$ motion artifact, and dendrites well isolated from other fluorescent structures) were used in the blinded analysis. Green fluorescent protein (GFP)-labeled neurons were first imaged at low resolution $(620 \times 620 \mu \mathrm{m}$ FOV, $0.6 \mu \mathrm{m} /$ pixel in $X Y$, 2.5- $\mu \mathrm{m}$ Z-step size) down to $600-700 \mu \mathrm{m}$ to capture all of the cell's dendritic processes and assay cell subtype by morphology, primary apical bifurcation depth, and soma depth (Holtmaat et al., 2006). The apical dendrites from complex-tufted neurons, the corticospinal neurons projecting to the spinal cord and thalamus in M1, were selected based on their large highly ramified dendritic trees, deep primary apical bifurcation, and thick dendrites, and re-imaged at high resolution $(310 \times 310$ to $420 \times 420 \mu \mathrm{m}$ FOV, $0.1 \mu \mathrm{m} /$ pixel, $1 \mu \mathrm{m} Z$-step size) to adequately capture individual dendritic spines. Laser power was maintained under $20 \mathrm{~mW}$ (average $\sim 10 \mathrm{~mW}$ ) during image stack acquisition.

\section{Analysis of structural plasticity}

Raw z stacks were denoised by a custom polynomial interpolation method (Jiang et al., 2013). Spine formation, elimination, and stabilization were quantified with a custom MATLAB user interface and ImageJ (MicroBrightField). Terminal dendrite segments which were well-visualized at all time points were chosen for analysis. Sections of dendrite occluded by other fluorescent structures or blood vessels were excluded from the analysis. Because of in vivo two-photon microscopy's relatively poor resolving power in the $z-$ axis, only structures protruding laterally along the $X-Y$ 


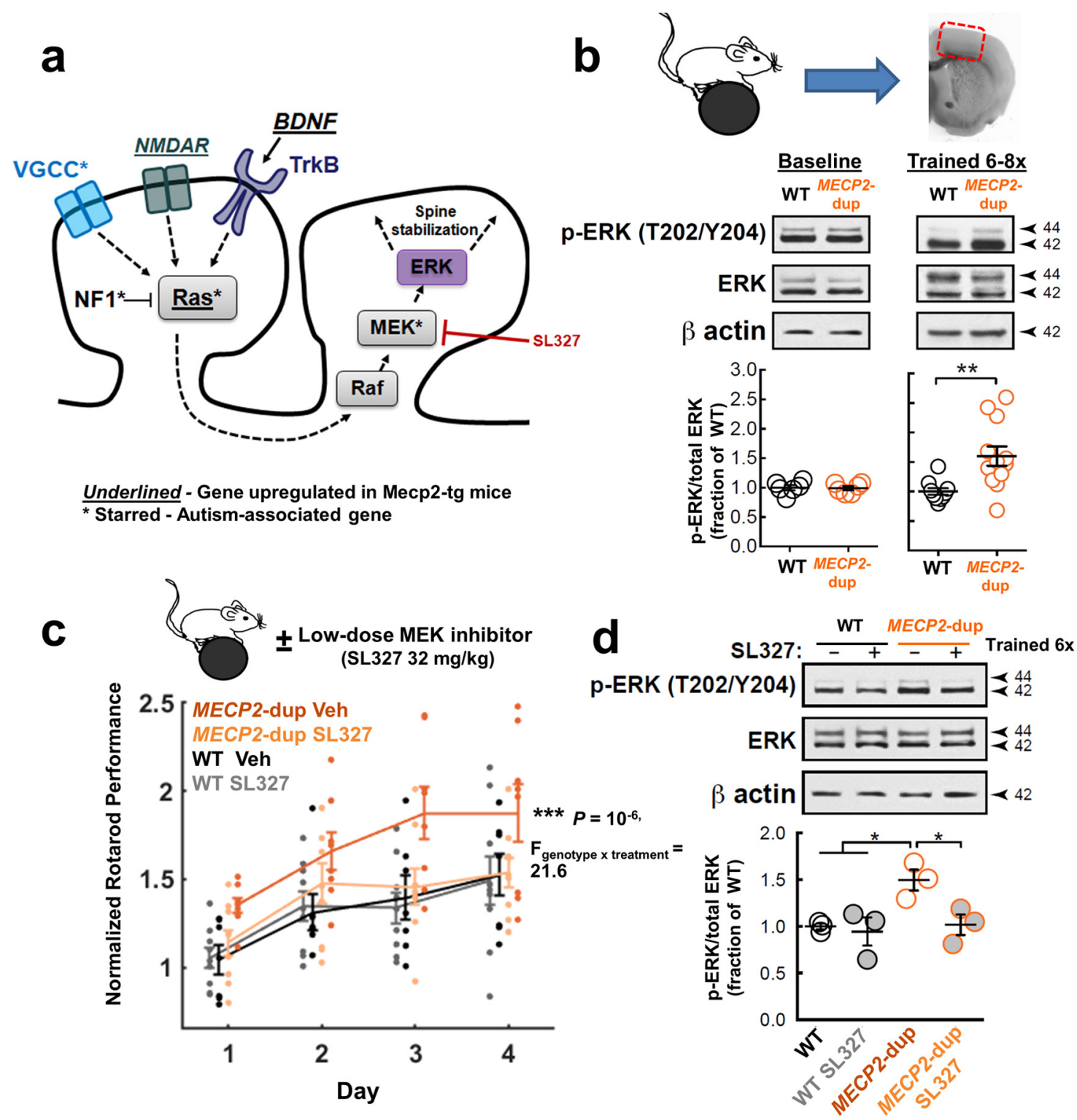

Figure 1. Normalization of enhanced motor learning by pharmacological inhibition of elevated Ras-ERK signaling in MECP2-duplication mice. a, A simplified schema of the Ras-MAPK signaling pathway and how it is hypothesized to contribute to clustered-spine stabilization. Genes transcriptionally upregulated in MECP2-overexpressing mice are underlined. Known autism-associated genes are denoted with an asterisk. $\boldsymbol{b}$, Rotarod training (six to eight trials) induces enhanced Ras-MAPK signaling (ERK phosphorylation) in MECP2-duplication mice relative to WT littermates, despite equivalent baseline levels before training. Representative Western blottings and densitometric quantification of ERK activation (p-ERK T202/Y204/total ERK immunoreactivity; 42- and 44-kDa bands summed in quantification) at baseline ( $n=6$ mice/genotype; unpaired two-sided $t$ test: $\left.p=0.9, t_{(10)}=0.17\right)$ and after training $(n=10$ WT and 12 MECP2-duplication mice; unpaired two-sided $t$ test: $\left.{ }^{* *} p=0.004, t_{(20)}=3.2\right)$. Data are presented as fraction of the WT mean for illustration purposes. Statistical tests were performed on raw per-animal p-ERK immunoreactivity/total-ERK immunoreactivity values. Time spent on the rotarod did not explain differences between genotypes (see text). c, The MEK inhibitor SL327 normalizes rotarod performance in MECP2-duplication mice. SL327 or vehicle was injected intraperitoneally 30 min before training on each training day. Mean \pm SEM of the peak performance on each day plotted for vehicle-treated MECP2-duplication (dark orange, $n=8$ mice), vehicle-treated WT (black, $n=7$ ), SL327-treated MECP2-duplication (pale orange, $n=9$ ), and SL327-treated WT (gray, $n=9$ ) mice. For illustration purposes, rotarod performance for each animal was normalized to the mean first-day performance of the WT littermates in that animal's cohort before averaging across animals, to account for systematic variability in performance across cohorts because of animal weight and age; ${ }^{* \star} p=10^{-6}$, genotype $\times$ drug interaction, $F_{\text {genotype }} \times \operatorname{treatment}(1,1,29)=21.6 ; F_{\text {genotype }(1,29)}=$ $6.4, p=0.01 ; F_{\text {treatment(1,29) }}=4.9, p=0.027 ; F_{\text {trial(15,29) }}=15.8, p=10^{-6}$; mixed effects repeated-measures ANOVA. Statistical analysis was performed on raw per-trial rotarod performance values. Litter was included as an interacting variable to control for across-litter variability in performance. $\boldsymbol{d}$, Consistent with a role for elevated ERK signaling in the mutant's enhanced motor learning phenotype, $32 \mathrm{mg} / \mathrm{kg}$ SL327 treatment blocked the training-dependent increase in M1 ERK phosphorylation in MECP2-duplication mice. Representative Western blottings and densitometric quantification of ERK activation in vehicle-treated versus SL327-treated WT and MECP2-duplication mice ( $n=3$ mice/genotype/treatment group; ${ }^{*} p<0.05, F_{\text {genotype(1,8) }}=6.7, F_{\text {treatment }(1,8)}=5.9, F_{\text {interaction }(1,1,8)}$ 
continued

$=3.7$, two-way ANOVA with Tukey's post hoc correction for multiple comparisons. Normalization of data points as in $\boldsymbol{b}$. Mice in the vehicle-treated condition are also included in $\boldsymbol{b}$. Error bars represent SEM. Circles show data points from individual animals. Example full length Western blottings are shown in Extended Data Figure 1-1a,b. For blinding procedure, see Materials and Methods.
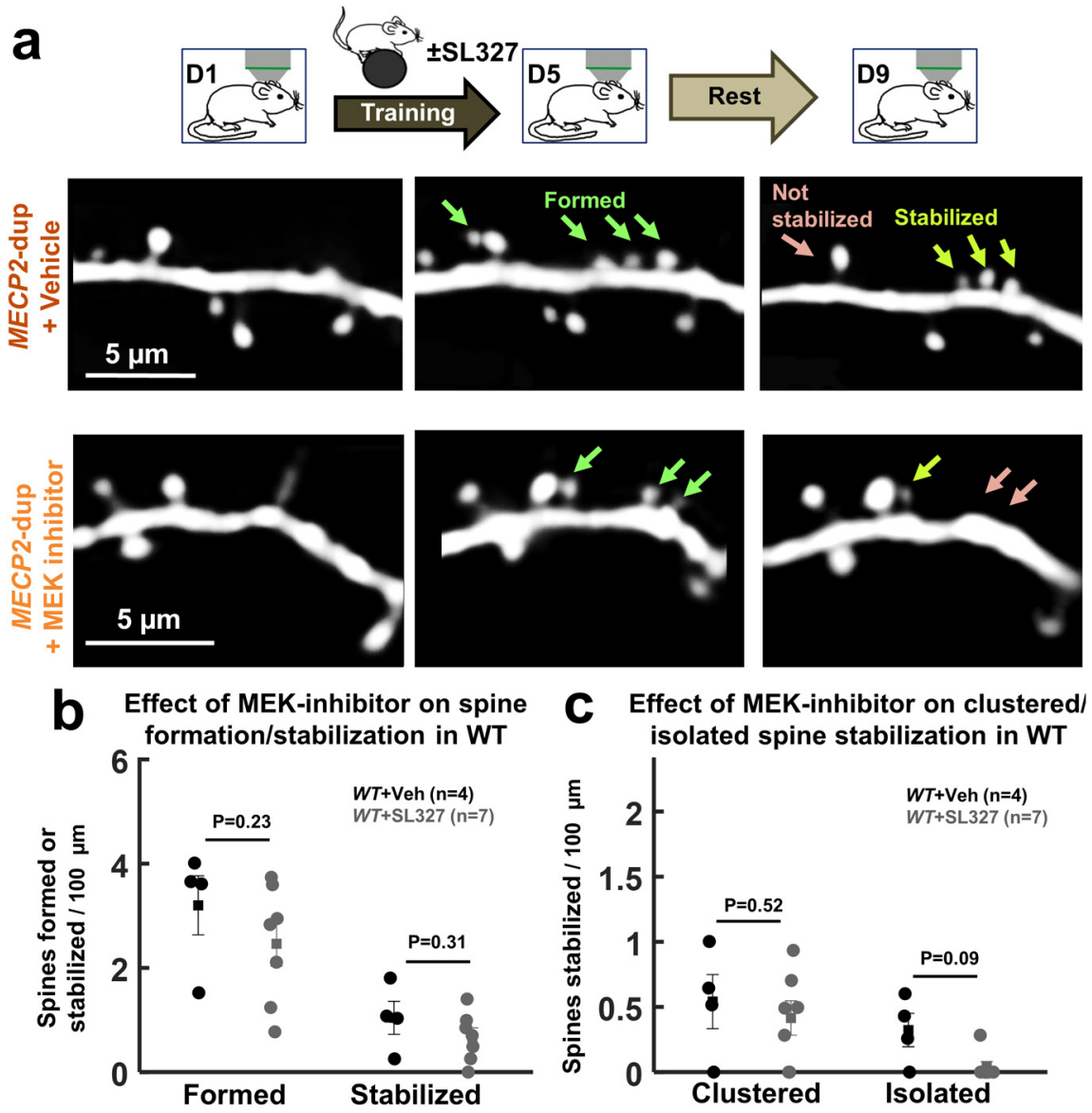

d Effect of MEK-inhibitor on spine

Effect of MEK-inhibitor on clustered/
isolated spine stabilization in mutants
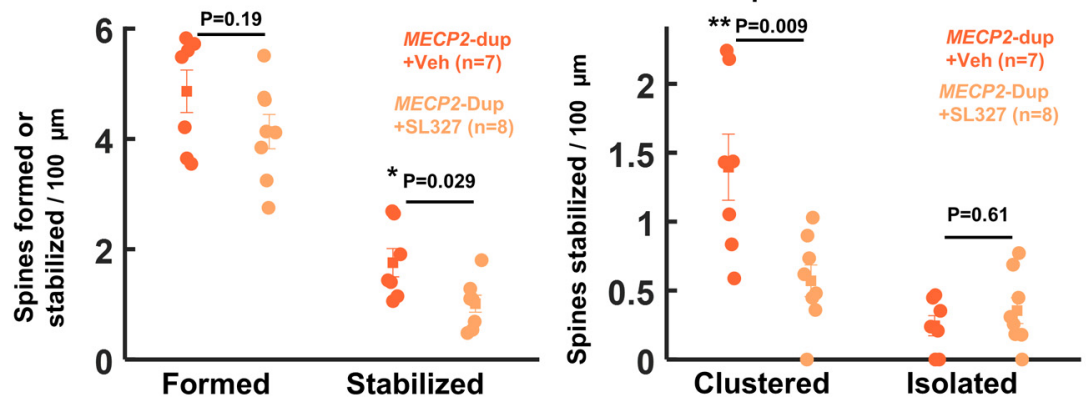

Figure 2. Normalization of excessive clustered spine stabilization in MECP2-duplication mice by pharmacological Ras-ERK inhibition. a, Sample images of dendritic segments imaged before rotarod training (left), following $4 \mathrm{~d}$ of training (middle), and $4 \mathrm{~d}$ after the end of training (right) demonstrating decreased clustered spine stabilization in SL327-treated (bottom) versus vehicle-treated (top) MECP2-duplication mice. $\boldsymbol{b}$, Total spines formed (left bars) and spines stabilized (right bars) per $100 \mu \mathrm{m}$ in vehicle-treated (black, $n=4$ animals, 57 spines formed, 30 dendritic segments) and SL327-treated (gray, $n=7$ animals, 49 spines formed, 49 dendritic segments) littermate control mice. c, Clustered and isolated new-spines stabilized per $100 \mu \mathrm{m}$ in vehicle-treated (black) and SL327treated (gray) littermate control mice. $\boldsymbol{d}$, Total spines formed (left bars) and spines stabilized (right bars) per $100 \mu \mathrm{m}$ in vehicletreated (dark orange, $n=7$ animals, 184 spines formed, 54 dendritic segments) and SL327-treated (light orange, $n=8$ animals, 143 spines formed, 50 dendritic segments) MECP2-duplication mice. e, Clustered and isolated spines stabilized per $100 \mu \mathrm{m}$ in vehicletreated (dark orange) and SL327-treated (light orange) MECP2-duplication mice. Note that there are significantly fewer stabilized clustered spines in SL327 treated animals; ${ }^{\star} p<0.05$, ${ }^{\star *} p<0.01$, specific $p$ values reported in the figure, Mann-Whitney $U$ test. 
plane were included in the analysis, following the standard in this field (Holtmaat et al., 2009). For a protrusion to be selected for analysis it had to project out of the dendritic shaft by at least 4 pixels $(\sim 0.4 \mu \mathrm{m})$, which corresponds approximately to 2 SDs of the noise blur on either side of the dendritic shaft. Spines were initially identified at one time point, by moving up and down through individual slices in each Z stack, and the same region of dendrite was examined at other time points to identify the first (formation) and last (elimination) time that the spine was present. Custom MATLAB routines analyzed the stability/survival of each formed spine. Filopodia, which are rare at the analyzed age, were identified morphologically, based on their long length (usually $>4 \mu \mathrm{m}$ ), curved shape, and lack of a distinct head (Zuo et al., 2005) and excluded from the analysis as in Yang et al. (2009). Each spine was classified as either clustered or isolated by calculating the distance to its nearestneighbor stabilized learning-associated spine as in $\mathrm{Fu}$ et al. (2012) and Ash et al. (2021).

\section{Motor training}

The Ugo Basile mouse rotarod was used for motor training. At least $2 \mathrm{~h}$ after imaging sessions, in the late afternoon, mice were placed on the rotarod, and the rotarod gradually accelerated from 5 to $80 \mathrm{rpm}$ over $3 \mathrm{~min}$. Up to five littermate mice with intermixed genotypes were trained in parallel. Single-trial rotarod performance was quantified as the time right before falling or holding on to the dowel rod for two complete rotations without regaining footing. A 5- to 10-min rest period occurred between each trial. Four trials were performed per day. For immunoblot experiments measuring M1 ERK phosphorylation with rotarod training, training-naive mice were trained six to eight times consecutively (Fig. 1b,d). For the pharmacology experiments demonstrating the effect of the specific MEK inhibitor SL327 on rotarod performance, the peak performance of each animal on each day, normalized to the vehicle-treated wild-type (WT) mean to account for across litter variability in performance, was used in the analysis (median performance yielded similar statistically significant results).

\section{Pharmacological Ras-MAPK inhibition}

The centrally-acting selective MEK inhibitor SL327 (Atkins et al., 1998; Axonmedchem \#1122) was injected intraperitoneally at $32 \mathrm{mg} / \mathrm{kg}$ (in $16 \mathrm{mg} / \mathrm{ml}$ DMSO) $30 \mathrm{~min}$ before rotarod training (Bureau et al., 2010). This dose was selected to be low as it is known to minimally affect motor performance in WT animals (Bureau et al., 2010).

\section{Immunoblots}

Deeply anesthetized (isoflurane) four- to five-monthold MECP2-duplication mice and littermate controls were killed 30 min after training and their brains were rapidly dissected on a glass plate over ice. The motor cortex from each hemisphere was isolated from the remaining cortical tissue and lysed in ice-cold homogenization buffer (200 mm HEPES, 50 mm NaCl, 10\% glycerol, 1\% Triton X-100, $1 \mathrm{~mm}$ EDTA, $50 \mathrm{~mm} \mathrm{NaF,} 2 \mathrm{~mm}$ $\mathrm{Na}_{3} \mathrm{VO}_{4}, 25 \mathrm{~mm} \beta$-glycerophosphate, and $1 \times$ EDTAfree complete ULTRA protease inhibitor cocktail tablets; Roche). Insoluble material was removed by centrifugation at $14,000 \times g$ for $10 \mathrm{~min}$ at $4^{\circ} \mathrm{C}$. Protein concentration of the resulting supernatant was determined by Bradford assay (Bio-Rad, reagent 500-0006) and lysates were then diluted in $2 \times$ Laemmli Buffer. A total of $30 \mu \mathrm{g}$ protein/sample was resolved by SDSPAGE (12.5\% acrylamide) and gel contents were transferred to nitrocellulose membranes. Membranes were blocked $30 \mathrm{~min}$ in 5\% milk, 0.2\% Tween 20 tris-buffered saline (TBST). To assess ERK phosphorylation, membranes were first probed overnight at $4^{\circ} \mathrm{C}$ with phospho-specific rabbit anti-phospho-p44/42 MAPK/Erk1/2 (Cell Signaling Technology, \#4370, 1:1000). Blots were then incubated with HRP-conjugated goat anti-rabbit secondary antibody (Jackson ImmunoResearch, 111035-144, 1:5000) for $1 \mathrm{~h}$ at room temperature followed by incubation in Super-Signal West Femto kit substrate (Thermo Scientific, 34096) per the manufacturer's instructions. Film was exposed to the Super-Signaltreated membranes and then developed. Membranes were then stripped $(1.5 \%$ glycine and $2.9 \% \mathrm{NaCl}$, $\mathrm{pH} 2.8)$, blocked with $5 \%$ milk TBST, then re-probed overnight with rabbit anti-MAPK/ERK1/2 (Cell Signaling Technologies, \#9202, 1:1000) to assess total ERK protein levels. $\beta$-Actin levels were measured as an additional loading control (mouse anti- $\beta$-actin, Millipore, MAB1501, 1:5000). The goat anti-mouse secondary antibody was diluted $1: 10,000$ for the $\beta$-actin blots. Band density was quantified in ImageJ (NIH).

\section{Image presentation}

Dendritic spine images are displayed as "best" projection mosaics (Holtmaat et al., 2009). Extraneous fluorescence is masked and images are slightly smoothed for illustration purposes only.

\section{Statistical tests}

Statistical significance between unpaired normal samples was assessed by Mann-Whitney $U$ test or twoway ANOVA, except where noted, using MATLAB. Enhanced rotarod performance in MECP2-duplication mice in Figure 1 was tested by repeated-measures ANOVA. Effect of SL327 on rotarod performance in MECP2-duplication mice compared with littermate controls was evaluated by determining the genotype $\times$ treatment interaction term using a mixed effects repeated-measures ANOVA in $R$ statistics software. Statistical analysis was performed on raw per-trial rotarod performance values. Litter was included as a term to control for across-litter variability in performance; ${ }^{*} p \leq 0.05,{ }^{* *} p \leq 0.01,{ }^{* * *} p \leq 0.001$. All results are reported as mean \pm SEM, unless otherwise noted. 


\section{Results}

ERK signaling has been shown to promote cooperative plasticity between dendritic spines located at close proximity $(9-10 \mu \mathrm{m})$ to each other along the dendrite (Harvey and Svoboda, 2007; Harvey et al., 2008). This led us naturally to hypothesize that it mediates the enhanced clustered dendritic spine stabilization previously observed in MECP2-duplication animals (Ash et al., 2021). The experiments described below were targeted a-priori to examine this primary hypothesis.

\section{Enhanced motor learning in MECP2-duplication mice is normalized by Ras-ERK inhibition}

A simplified sketch of ERK signaling in clustered-spine plasticity is illustrated in Figure 1a, adapted from (Harvey et al., 2008; Ye and Carew, 2010). Several genes in the ERK pathway are associated with autism (Stornetta and Zhu, 2011; Fig. 1a, asterisks) and MECP2-duplication mice overexpress several genes in this pathway (Chahrour et al., 2008; notably, Bdnf, Nmdar1, and Ras; Fig. 1a, underlined). To directly test whether ERK signaling is increased in motor cortex of MECP2-duplication mice, we performed Western blot analyses on M1 protein extracts isolated from mutant mice and WT littermates at baseline and immediately following rotarod training (Fig. 1b; Extended Data Fig. 1-1a, six to eight consecutive trials in previously-untrained animals). We found that marked hyperphosphorylation of the MAP kinase ERK1/2 (T202/Y204) in MECP2-duplication mouse area $\mathrm{M} 1$ occurred with rotarod training $(p=0.004, n=10$ WT M1 extracts from 10 mice, 12 MECP2-duplication M1 extracts from 12 mice, two-tailed unpaired $t$ test; Fig. 1b). In contrast the phosphorylation state of ERK was not significantly altered in mutant M1 lysates without training $(p=0.87, n=6$ mice per genotype, two-tailed unpaired $t$ test; Fig. 1b), as reported previously for untrained Mecp2null and MECP2-duplication animals (Pitcher et al., 2015). Note that the increase in ERK phosphorylation in area M1 after motor training in MECP2-animals could not be explained solely by increased time spent on the rotarod, as the level of phosphorylation did not correlate with the latency to fall from the rotarod $(r=-0.17, p=0.53)$. This suggests the induction of ERK phosphorylation by training is exuberant in the motor cortex of MECP2-duplication animals.

Training-induced ERK hyperphosphorylation (Fig. 1b) coupled with the increased clustered-spine stabilization previously observed in MECP2-duplication animals (Ash et al., 2021) implicated elevated ERK signaling in the enhanced motor learning phenotype of the MECP2-duplication syndrome mouse model (Collins et al., 2004; Harvey et al., 2008). To test this hypothesis, in a new round of experiments we administered a low dose $(32 \mathrm{mg} / \mathrm{kg}$, i.p.) of the specific centrally-acting MEK inhibitor SL327 or DMSO vehicle 30 min before rotarod training on each day (Bureau et al., 2010), and trained the animals for four consecutive trials daily for four days in a row (Collins et al., 2004; Ash et al., 2021). This dose was chosen to ensure effects on locomotor function in WT are minimal (Antoine et al., 2013; but see Bureau et al., 2010). Accordingly, the performance of WT mice was not affected, whereas SL327 reversed the enhanced motor learning in mutants $\left(p=10^{-6}\right.$, genotype $\times$ drug interaction, $F_{\text {genotype }} \times$ treatment $=$ 21.6, $n=7-9$ mice per group, mixed effects repeated-measures ANOVA; Fig. 1c). Furthermore, M1 ERK phosphorylation was normalized in SL327-treated mutants versus vehicle-treated mutants (Fig. 1d; Extended Data Fig. 1-1b, $p<0.05, n=3$ mice/group, two-way ANOVA with Tukey's post hoc correction for multiple comparisons), confirming the effectiveness of the inhibitor in reducing ERK phosphorylation levels.

\section{Enhanced clustered spine stabilization in MECP2- duplication mice is normalized by Ras-ERK inhibition}

Lastly, we measured the effect of MEK inhibition on clustered spine stabilization in MECP2-duplication mice and littermate controls crossed to the thy1-GFP $M$ line, which sparsely expresses GFP in layer 5 pyramidal neurons (Feng et al., 2000). As in Ash et al. (2021), chronic cranial windows were implanted over primary motor cortex (M1) in MECP2-duplication mice and littermate controls, and apical dendrites from GFP-expressing L5 pyramidal neurons were imaged with in vivo two-photon microscopy (Holtmaat et al., 2009). Spine analysis was performed on terminal dendritic branches of the apical tuft of these neurons. We first identified baseline spines, then animals were trained on the rotarod task (four trials per day) for $4 \mathrm{~d}$ (Fig. 2A). Animals were randomized to receive SL327 $32 \mathrm{mg} / \mathrm{kg}$ or vehicle (DMSO) injected intraperitoneally $30 \mathrm{~min}$ before training across the four rotarod training days. On the fifth day, dendrites were imaged again to identify new spines formed. Following $4 \mathrm{~d}$ of rest, dendrites were once again imaged to identify the new spines that stabilized. The follow-up imaging time point was chosen in line with prior studies showing that the vast majority of newly formed dendritic spines which persist for at least $4 \mathrm{~d}$ form an electron-microscopy-verified synapse (Knott et al., 2006). Each stabilized spine was classified as clustered or isolated based on its proximity to another newly-formed spine on the same dendrite (clustered: $<9 \mu \mathrm{m}$ interspine distance; isolated: $\geq 9-\mu \mathrm{m}$ interspine distance, following Ash et al., 2021).

As observed previously (Ash et al., 2021), clustered spine stabilization was increased in vehicle-treated MECP2-duplication mice compared with controls (WT $1.1 \pm 0.2$ stabilized per $100 \mu \mathrm{m}, \mathrm{n}=4$ animals, 30 dendritic segments; MECP2-duplication: $2.2 \pm 0.4$ stabilized per $100 \mu \mathrm{m}, n=7$ animals, 54 dendritic segments, $p=0.04$, Mann-Whitney $U$ test; two-way ANOVA effect of genotype: $\left.p=0.03, F_{(1,22)}=5.5\right)$. Overall spine formation/stabilization as well as clustered and isolated spine stabilization were not significantly affected by MEK inhibition in control mice (all $p$ values $>0.09$, Mann-Whitney $U$ test, $n=4$ vehicle-treated WT mice, 7 SL327-treated WT mice; Fig. 2b, c), as expected given the low dose of SL327 (Antoine et al., 2013). In contrast, in MECP2-duplication animals overall spine stabilization was significantly reduced by SL327 (effect on stabilization: $p=0.029$, Mann-Whitney $U$ test; two-way ANOVA effect of SL327: $p=0.02, F_{(1,22)}=$ 6.2 ; interaction: $p=0.4 ; n=7$ vehicle-treated MECP2- 
duplication mice, $n=8$ SL327-treated MECP2-duplication mice; Fig. 2d), back to levels similar to that of WT controls (SL327-treated mutant spine stabilization rate: $1.0 \pm 0.2$ per $100 \mu \mathrm{m}$; vehicle-treated WT spine stabilization rate: $1.0 \pm 0.3$ per $100 \mu \mathrm{m}$, vehicle-treated mutant spine stabilization rate: $1.7 \pm 0.2$ ). Separating stabilized spines into clustered and non-clustered subgroups revealed that this SL327-induced decrease in spine stabilization was mediated entirely by a reduction in the stabilization of clustered spines $(p=0.009$, Mann-Whitney $U$ test, Cohen's $d=1.65$; two-way ANOVA effect of SL327: $p=0.01, F_{(1,22)}=7.7$, effect of SL327; effect of genotype: $p=0.01, F_{(1,22)}=7.7$; Interaction: $p=0.06, F_{(1,22)}=$ 3.7; $n=7$ vehicle-treated MECP2-duplication mice, $n=8$ SL327-treated MECP2-duplication mice; Fig. 2e). SL327 had a negligible effect on the stabilization of isolated new-spines in mutants $(p=0.61$, Mann-Whitney $U$ test, Cohen's $d=0.3$ ) and also did not affect significantly overall spine formation (effect on mutant formation: $p=0.19$, Mann-Whitney $U$ test; two-way ANOVA effect of SL327: $p=0.09$; effect of genotype: $p=0.0006$, $F_{(1,22)}=15.9$; interaction: $p=0.9$; Fig. $\left.2 d\right)$. Interestingly, there was a trend toward decreased stabilization of isolated spines in SL327-treated WT mice not seen in mutants (genotype $\times$ SL327 interaction: $p=0.03, F_{(1,22)}=$ $5.2)$, although this trend did not survive pairwise comparison ( $p>0.1$, Mann-Whitney $U$ test). These observations suggest that elevated ERK signaling contributes to the structural stabilization of training-associated clustered synapses in the MECP2-duplication mouse.

\section{Discussion}

In summary, we found that the ERK pathway, a major regulator of clustered spine stabilization (Harvey et al., 2008; Frank et al., 2018), is hyperactive following training in MECP2-duplication mouse motor cortex, and both increased spine-cluster stabilization and enhanced motor learning in MECP2-duplication mice can be reversed by ERK-specific pharmacologic inhibition.

Our results build on a growing evidence base implicating Ras-ERK/MAPK signaling in ASD (Vithayathil et al., 2018). Mutations in Ras-MAPK pathway genes including NF1, Ras, MEK, and RSK, together referred to as Rasopathies, cause syndromic autism (Stornetta and Zhu, 2011). Pathway analyses of large scale genome sequencing data confirm that Ras-MAPK pathway mutations are enriched in idiopathic autism (Wen et al., 2016; Mitra et al., 2017), and upregulations in RasMAPK pathway activity correlate with symptom severity in autism patients (Rosina et al., 2019). Multiple animal models of autism demonstrate abnormalities in RasMAPK signaling including Rett syndrome (Mellios et al., 2018), BTBR strain (Seese et al., 2014; Cheng et al., 2017), 16p11 del (Pucilowska et al., 2015), fragile $X$ syndrome (Soong et al., 2008), neurofibromatosis type 1 (Costa et al., 2002), Noonan syndrome (Lee et al., 2014), Costello syndrome (Schreiber et al., 2017), cardio-cutaneo-facial syndrome (Anastasaki et al., 2009), and SynGAP1 syndrome (Rumbaugh et al., 2006). Autism-associated phenotypes have been shown to be rescued by inhibition of Ras-ERK signaling in many of these animal models (Wang et al., 2012; Pucilowska et al., 2018; Moreau et al., 2020; Mullins, 2020). Our results provide the first evidence that Ras-ERK signaling is upregulated following training in the mouse model for MECP2-duplication syndrome, and that its abnormally enhanced motor learning phenotype can be rescued by inhibiting ERK signaling (Fig. 1).

Essentially all autism models that have been formally tested exhibit changes in synaptic plasticity and learning (Bourgeron, 2015), including MECP2-duplication mice (Collins et al., 2004; Na et al., 2012; Jiang et al., 2013; Ash et al., 2018). In prior work, it was shown that clustered spine consolidation is abnormally enhanced in MECP2duplication animals (Ash et al., 2021). Here, we show that MECP2-duplication clustered spine consolidation returned to WT-like levels after normalizing ERK signaling with the specific pharmacological inhibitor SL327 (Fig. 2). Furthermore, this occurred at a dose that did not alter the rate of new spine formation or the rate of new isolated spine consolidation after training, so the observed effect appears to be specific to co-operative spine consolidation. These observations forge a link between increased ERK signaling, increased clustered spine consolidation, and enhanced learning phenotype in the MECP2-duplication mouse model of syndromic autism.

Our results align with converging evidence on the role of ERK signaling in dendritic spine clustering and autism pathophysiology. Multiple links in the Ras-ERK pathway including BDNF, TrkB, Ras, and ERK are required for clustered spine consolidation ex vivo (Harvey et al., 2008; Niculescu et al., 2018), and CCR5-mutant animals engineered to have hyperactive Ras-ERK signaling exhibit increased clustered spine plasticity (Frank et al., 2018). Our contribution adds to this work, showing that the excessive clustered spine stabilization previously observed in the MECP2-duplication syndrome mouse model (Ash et al., 2021) can be normalized in vivo with a pharmacological inhibitor of ERK signaling.

One remaining puzzle is the fact that excessive clustered spine stabilization in MECP2-duplication animals occurs both with and without training (Ash et al., 2021), whereas excessive ERK phosphorylation occurred with training but not without training (Fig. 1b; Pitcher et al., 2015). It is possible that a subtle elevation in Ras-MAPK signaling (ERK phosphorylation) may be present without training, but not be enough to be detected by Western blot analysis (White and Wolf-Yadlin, 2016), as any difference at baseline would likely be small given our data (Fig. $1 b)$. Other nonexclusive possibilities include that downstream effectors of p-ERK are nonlinearly affected by Ras-ERK activity in MECP2-duplication mice, and/or they can still be activated through ERK-independent mechanisms without training. Finally, Ras-ERK inhibition may modulate motor learning and spine consolidation through mechanisms other than Ras's role in dendritic spines. Ras-ERK modulates learning and plasticity in the brain through multiple presynaptic and postsynaptic mechanisms in both excitatory and inhibitory neurons (Ryu and Lee, 2016). It is not inconceivable, for example, that MEK 
inhibition could downregulate spontaneous activity or alter modulatory neurotransmitter release (Ding et al., 2011; Borges et al., 2017), which would in turn indirectly normalize enhanced learning and clustered spine consolidation.

Importantly, we note that we have not conclusively shown that clustered spine stabilization drives enhanced learning, although others previously showed a correlation between spine clustering and learning across animals (Frank et al., 2018; Ash et al., 2021). The fact that the MEK inhibitor normalized motor performance in MECP2-duplication mice even on the first day of training (Fig. 1C), at which point clustered spine stabilization is unlikely to play a significant role, suggests that excessive Ras-MAPK signaling boosts learning in mutants through multiple mechanisms. Verifying a causal link between clustered spine consolidation and learning is an important goal of future work. Finally, we note that in our preparation $32 \mathrm{mg} / \mathrm{kg}$ SL327 did not significantly affect WT rotarod performance or M1 ERK phosphorylation, which aligns with (Antoine et al., 2013) but disagrees somewhat with (Bureau et al., 2010), who reported that $30 \mathrm{mg} / \mathrm{kg}$ SL327 was sufficient to decrease rotarod performance in WT mice and decrease ERK phosphorylation in the striatum. It is possible that subtle differences in the rotarod training parameters (four trials per day for $4 \mathrm{~d}$, accelerating from 5 to $80 \mathrm{rpm}$ in $3 \mathrm{~min}$ in our paradigm, vs 10 trials per day for $4 \mathrm{~d}$, from 4 to $40 \mathrm{rpm}$ in $5 \mathrm{~min}$ in their paradigm) and probing for ERK in different brain areas could explain these discrepancies, but this requires follow-up experimental assessment to determine under which conditions SL327 does or does not affect WT learning and memory.

Although enhanced motor learning is not observed in human patients (Ramocki et al., 2010), it is possible that the structural abnormality we describe in mice is also operating in the humans, but manifests with a different developmental trajectory of motor deterioration because of species-specific differences in motor system development and function (Collins et al., 2004; Ramocki et al., 2009). We note again here that several autism mouse models including MECP2-duplication, neuroligin-3, 15q duplication, PTEN, CNTNAP2, and CCR5 have enhanced motor learning and plasticity (Etherton et al., 2011; Piochon et al., 2014; Rothwell et al., 2014; Frank et al., 2018), while several other mouse models including Rett syndrome, fragile $X$, and Angelman (15q deletion), have impaired motor learning and plasticity ( $\mathrm{Li}$ et al., 2002; Asaka et al., 2006; Van Woerden et al., 2007; Kondo et al., 2008; Padmashri et al., 2013). In particular, opposite to our findings in the MECP2-duplication mice, it was recently reported that fragile $\mathrm{X}$ mice have impaired motor learning and decreased clustered spine stabilization (Bhattacharya et al., 2012; Padmashri et al., 2013; Reiner and Dunaevsky, 2015). Building on other studies positing an axis of synaptic pathophysiology in syndromic autism (Auerbach et al., 2011), these findings together suggest that certain forms of syndromic autism defined by enhanced plasticity and prominent behavioral inflexibility could be particularly amenable to Ras-MAPK modulating agents.
Our results provide in vivo evidence that ERK signaling is involved in learning-associated synaptic stabilization and synaptic clustering and suggest that a training-dependent increase in M1 ERK signaling facilitates procedural motor memory consolidation in MECP2-duplication animals. Our findings provide additional support to hypotheses that learning phenotypes in autism arise from disrupted Ras-ERK signaling and synaptic plasticity (Bourgeron, 2015; Vithayathil et al., 2018). In the future, it will be fruitful to study the regulation of upstream and downstream mediators of ERK signaling in MECP2-duplication mice and explore how excessive ERK signaling contributes to excessive clustered spine stabilization in this mouse model (Alonso et al., 2004; Im et al., 2010; Ye and Carew, 2010; Stornetta and Zhu, 2011; Ebert and Greenberg, 2013; Niculescu et al., 2018). In the future, modulation of structural plasticity through Ras-MAPK inhibitors could provide a potential therapeutic avenue for behavioral inflexibility and other phenotypes in the MECP2-duplication syndrome (Sandweiss et al., 2020).

\section{References}

Achilly NP, Wang W, Zoghbi HY (2021) Presymptomatic training mitigates functional deficits in a mouse model of Rett syndrome. Nature 592:596-595.

Alonso M, Medina JH, Pozzo-Miller L (2004) ERK1/2 activation is necessary for BDNF to increase dendritic spine density in hippocampal CA1 pyramidal neurons. Learn Mem 11:172-178.

Anastasaki C, Estep AL, Marais R, Rauen KA, Patton EE (2009) Kinase-activating and kinase-impaired cardio-facio-cutaneous syndrome alleles have activity during zebrafish development and are sensitive to small molecule inhibitors. Hum Mol Genet 18:2543-2554.

Antoine MW, Hübner CA, Arezzo JC, Hébert JM (2013) A causative link between inner ear defects and long-term striatal dysfunction. Science 341:1120-1123.

Asaka Y, Jugloff DGM, Zhang L, Eubanks JH, Fitzsimonds RM (2006) Hippocampal synaptic plasticity is impaired in the Mecp2-null mouse model of Rett syndrome. Neurobiol Dis 21:217-227.

Ash RT, Fahey PG, Park J, Zoghbi HY, Smirnakis SM (2018) Increased axonal bouton stability during learning in the mouse model of MECP2 duplication syndrome. eNeuro 5:ENEURO.005617.2018.

Ash RT, Park J, Suter B, Smirnakis SM, Zoghbi HY (2021) Excessive formation and stabilization of dendritic spine clusters in the mecp2-duplication syndrome mouse model of autism. eNeuro 8: ENEURO.0282-20.2020.

Atkins CM, Selcher JC, Petraitis JJ, Trzaskos JM, Sweatt JD (1998) The MAPK cascade is required for mammalian associative learning. Nat Neurosci 1:602-609.

Auerbach BD, Osterweil EK, Bear MF (2011) Mutations causing syndromic autism define an axis of synaptic pathophysiology. Nature 480:63-68.

Bhattacharya A, Kaphzan H, Alvarez-Dieppa AC, Murphy JP, Pierre $P$, Klann E (2012) Genetic removal of p70 S6 kinase 1 corrects molecular, synaptic, and behavioral phenotypes in fragile $X$ syndrome mice. Neuron 76:325-337.

Borges G, Miguelez C, Neto F, Mico JA, Ugedo L, Berrocoso E (2017) Activation of extracellular signal-regulated kinases (ERK 1/ 2 ) in the locus coeruleus contributes to pain-related anxiety in arthritic male rats. Int J Neuropsychopharmacol 20:463-475.

Bourgeron T (2015) From the genetic architecture to synaptic plasticity in autism spectrum disorder. Nat Rev Neurosci 16:551-563. 
Bureau G, Carrier M, Lebel M, Cyr M (2010) Intrastriatal inhibition of extracellular signal-regulated kinases impaired the consolidation phase of motor skill learning. Neurobiol Learn Mem 94:107-115.

Chahrour M, Sung YJ, Shaw C, Zhou X, Wong STC, Qin J, Zoghbi HY (2008) MeCP2, a key contributor to neurological disease, activates and represses transcription. Science 320:1224-1229.

Cheng N, Alshammari F, Hughes E, Khanbabaei M, Rho JM (2017) Dendritic overgrowth and elevated ERK signaling during neonatal development in a mouse model of autism. PLoS One 12: e0179409.

Collins AL, Levenson JM, Vilaythong AP, Richman R, Armstrong DL, Noebels JL, Sweatt JD, Zoghbi HY (2004) Mild overexpression of MeCP2 causes a progressive neurological disorder in mice. Hum Mol Genet 13:2679-2689.

Costa RM, Federov NB, Kogan JH, Murphy GG, Stern J, Ohno M, Kucherlapati R, Jacks T, Silva AJ (2002) Mechanism for the learning deficits in a mouse model of neurofibromatosis type 1. Nature 415:526-530.

Ding Y, Won L, Britt JP, Lim SAO, McGehee DS, Kang UJ (2011) Enhanced striatal cholinergic neuronal activity mediates L-DOPAinduced dyskinesia in parkinsonian mice. Proc Natl Acad Sci USA 108:840-845.

Ebert DH, Greenberg ME (2013) Activity-dependent neuronal signalling and autism spectrum disorder. Nature 493:327-337.

Etherton M, Földy C, Sharma M, Tabuchi K, Liu X, Shamloo M, Malenka RC, Südhof TC (2011) Autism-linked neuroligin-3 R451C mutation differentially alters hippocampal and cortical synaptic function. Proc Natl Acad Sci USA 108:13764-13769.

Feng G, Mellor RH, Bernstein M, Keller-Peck C, Nguyen QT, Wallace M, Nerbonne JM, Lichtman JW, Sanes JR (2000) Imaging neuronal subsets in transgenic mice expressing multiple spectral variants of GFP. Neuron 28:41-51.

Frank AC, Huang S, Zhou M, Gdalyahu A, Kastellakis G, Silva TK, Lu E, Wen X, Poirazi P, Trachtenberg JT, Silva AJ (2018) Hotspots of dendritic spine turnover facilitate clustered spine addition and learning and memory. Nat Commun 9:422.

Fu M, Yu X, Lu J, Zuo Y (2012) Repetitive motor learning induces coordinated formation of clustered dendritic spines in vivo. Nature 483:92-96.

Hao S, Tang B, Wu Z, Ure K, Sun Y, Tao H, Gao Y, Patel AJ, Curry DJ, Samaco RC, Zoghbi HY, Tang J (2015) Forniceal deep brain stimulation rescues hippocampal memory in Rett syndrome mice. Nature 526:430-434.

Harvey CD, Svoboda K (2007) Locally dynamic synaptic learning rules in pyramidal neuron dendrites. Nature 450:1195-1200.

Harvey CD, Yasuda R, Zhong H, Svoboda K (2008) The spread of Ras activity triggered by activation of a single dendritic spine. Science 321:136-140.

Holtmaat A, Wilbrecht L, Knott GW, Welker E, Svoboda K (2006) Experience-dependent and cell-type-specific spine growth in the neocortex. Nature 441:979-983.

Holtmaat A, Bonhoeffer T, Chow DK, Chuckowree J, De Paola V, Hofer SB, Hübener M, Keck T, Knott G, Lee WCA, Mostany R, Mrsic-Flogel TD, Nedivi E, Portera-Cailliau C, Svoboda K, Trachtenberg JT, Wilbrecht L (2009) Long-term, high-resolution imaging in the mouse neocortex through a chronic cranial window. Nat Protoc 4:1128-1144.

Im HI, Hollander JA, Bali P, Kenny PJ (2010) MeCP2 controls BDNF expression and cocaine intake through homeostatic interactions with microRNA-212. Nat Neurosci 13:1120-1127.

Jiang M, Ash RT, Baker SA, Suter B, Ferguson A, Park J, Rudy J, Torsky SP, Chao HT, Zoghbi HY, Smirnakis SM (2013) Dendritic arborization and spine dynamics are abnormal in the mouse model of MECP2 duplication syndrome. J Neurosci 33:19518-19533.

Knott GW, Holtmaat A, Wilbrecht L, Welker E, Svoboda K (2006) Spine growth precedes synapse formation in the adult neocortex in vivo. Nat Neurosci 9:1117-1124.

Kondo M, Gray LJ, Pelka GJ, Christodoulou J, Tam PPL, Hannan AJ (2008) Environmental enrichment ameliorates a motor coordination deficit in a mouse model of Rett syndrome - Mecp2 gene dosage effects and BDNF expression. Eur $\mathrm{J}$ Neurosci 27:3342-3350.

Kwon HB, Sabatini BL (2011) Glutamate induces de novo growth of functional spines in developing cortex. Nature 474:100-104.

Kwon CH, Luikart BW, Powell CM, Zhou J, Matheny SA, Zhang W, Li Y, Baker SJ, Parada LF (2006) Pten regulates neuronal arborization and social interaction in mice. Neuron 50:377-388.

Lee YS, Ehninger D, Zhou M, Oh JY, Kang M, Kwak C, Ryu HH, Butz D, Araki T, Cai Y, Balaji J, Sano Y, Nam C, Kim HK, Kaang BK, Burger C, Neel BG, Silva AJ (2014) Mechanism and treatment for learning and memory deficits in mouse models of Noonan syndrome. Nat Neurosci 17:1736-1743.

Li J, Pelletier MR, Perez Velazquez JL, Carlen PL (2002) Reduced cortical synaptic plasticity and GluR1 expression associated with fragile $X$ mental retardation protein deficiency. Mol Cell Neurosci 19:138-151.

Lu H, Ash RT, He L, Kee SE, Wang W, Yu D, Hao S, Meng X, Ure K, Ito-Ishida A, Tang B, Sun Y, Ji D, Tang J, Arenkiel BR, Smirnakis SM, Zoghbi HY (2016) Loss and gain of MeCP2 cause similar hippocampal circuit dysfunction that is rescued by deep brain stimulation in a Rett syndrome mouse model. Neuron 91:739-747.

Lyst MJ, Bird A (2015) Rett syndrome: a complex disorder with simple roots. Nat Rev Genet 16:261-274.

Makino H, Malinow R (2011) Compartmentalized versus global synaptic plasticity on dendrites controlled by experience. Neuron 72:1001-1011.

Mellios N, Feldman DA, Sheridan SD, Ip JPK, Kwok S, Amoah SK, Rosen B, Rodriguez BA, Crawford B, Swaminathan R, Chou S, Li Y, Ziats M, Ernst C, Jaenisch R, Haggarty SJ, Sur M (2018) MeCP2-regulated miRNAs control early human neurogenesis through differential effects on ERK and AKT signaling. Mol Psychiatry 23:1051-1065.

Mitra I, Lavillaureix A, Yeh E, Traglia M, Tsang K, Bearden CE, Rauen KA, Weiss LA (2017) Reverse pathway genetic approach identifies epistasis in autism spectrum disorders. PLoS Genet 13:e1006516.

Moreau MM, Pietropaolo S, Ezan J, Robert BJA, Miraux S, Maître M, Cho Y, Crusio WE, Montcouquiol M, Sans N (2020) Scribble controls social behaviors through the regulation of the ERK/Mnk1 pathway. bioRxiv 2020.09.10.289397.

Mostany R, Portera-Cailliau C (2008) A craniotomy surgery procedure for chronic brain imaging. J Vis $\operatorname{Exp}(12): 680$.

Mostany R, Portera-Cailliau C (2011) Absence of large-scale dendritic plasticity of layer 5 pyramidal neurons in peri-infarct cortex. $\mathrm{J}$ Neurosci 31:1734-1738.

Mullins CA (2020) Persistent behavior in a mouse model of autism: role of L-type calcium channels and striatum. Diss Abstr Int Sect B Sci Eng 77:816-822.

Na ES, Nelson ED, Adachi M, Autry AE, Mahgoub MA, Kavalali ET, Monteggia LM (2012) A mouse model for MeCP2 duplication syndrome: MeCP2 overexpression impairs learning and memory and synaptic transmission. J Neurosci 32:3109-3117.

$\mathrm{Na}$ ES, Morris MJ, Nelson ED, Monteggia LM (2014) GABAA a receptor antagonism ameliorates behavioral and synaptic impairments associated with MeCP2 overexpression. Neuropsychopharmacology 39:1946-1954.

Nakatani J, Tamada K, Hatanaka F, Ise S, Ohta H, Inoue K, Tomonaga S, Watanabe Y, Chung YJ, Banerjee R, Iwamoto K, Kato T, Okazawa M, Yamauchi K, Tanda K, Takao K, Miyakawa T, Bradley A, Takumi T (2009) Abnormal behavior in a chromosomeengineered mouse model for human 15q11-13 duplication seen in autism. Cell 137:1235-1246.

Niculescu D, Michaelsen-Preusse K, Güner Û, van Dorland R, Wierenga CJ, Lohmann C (2018) A BDNF-mediated push-pull plasticity mechanism for synaptic clustering. Cell Rep 24:20632074.

Padmashri R, Reiner BC, Suresh A, Spartz E, Dunaevsky A (2013) Altered structural and functional synaptic plasticity with motor skill learning in a mouse model of fragile $X$ syndrome. J Neurosci 33:19715-19723. 
Patterson MA, Szatmari EM, Yasuda R (2010) AMPA receptors are exocytosed in stimulated spines and adjacent dendrites in a RasERK-dependent manner during long-term potentiation. Proc Natl Acad Sci USA 107:15951-15956.

Peñagarikano O, Abrahams BS, Herman El, Winden KD, Gdalyahu A, Dong H, Sonnenblick LI, Gruver R, Almajano J, Bragin A, Golshani P, Trachtenberg JT, Peles E, Geschwind DH (2011) Absence of CNTNAP2 leads to epilepsy, neuronal migration abnormalities, and core autism-related deficits. Cell 147:235-246.

Piochon C, Kloth AD, Grasselli G, Titley HK, Nakayama H, Hashimoto K, Wan V, Simmons DH, Eissa T, Nakatani J, Cherskov A, Miyazaki T, Watanabe M, Takumi T, Kano M, Wang SSH, Hansel C (2014) Cerebellar plasticity and motor learning deficits in a copy-number variation mouse model of autism. Nat Commun 5:5586.

Pitcher MR, Herrera JA, Buffington SA, Kochukov MY, Merritt JK, Fisher AR, Schanen NC, Costa-Mattioli M, Neul JL (2015) Rett syndrome like phenotypes in the R255X Mecp2 mutant mouse are rescued by MECP2 transgene. Hum Mol Genet 24:2662-2672.

Pucilowska J, Vithayathil J, Tavares EJ, Kelly C, Colleen Karlo J, Landreth GE (2015) The 16p11.2 deletion mouse model of autism exhibits altered cortical progenitor proliferation and brain cytoarchitecture linked to the ERK MAPK pathway. J Neurosci 35:3190-3200.

Pucilowska J, Vithayathil J, Pagani M, Kelly C, Karlo JC, Robol C, Morella I, Gozzi A, Brambilla R, Landreth GE (2018) Pharmacological inhibition of ERK signaling rescues pathophysiology and behavioral phenotype associated with 16p11.2 chromosomal deletion in mice. J Neurosci 38:66406652.

Ramocki MB, Zoghbi HY (2008) Failure of neuronal homeostasis results in common neuropsychiatric phenotypes. Nature 455:912918.

Ramocki MB, Peters SU, Tavyev YJ, Zhang F, Carvalho CMB, Schaaf CP, Richman R, Fang P, Glaze DG, Lupski JR, Zoghbi HY (2009) Autism and other neuropsychiatric symptoms are prevalent in individuals with MECP2 duplication syndrome. Ann Neurol 66:771-782.

Ramocki MB, Tavyev YJ, Peters SU (2010) The MECP2 duplication syndrome. Am J Med Genet A 152A:1079-1088.

Reiner BC, Dunaevsky A (2015) Deficit in motor training-induced clustering, but not stabilization, of new dendritic spines in fmr1 knock-out mice. PLoS One 10:e0126572.

Rosina E, Battan B, Siracusano M, Di Criscio L, Hollis F, Pacini L, Curatolo P, Bagni C (2019) Disruption of mTOR and MAPK pathways correlates with severity in idiopathic autism. Transl Psychiatry 9:50.

Rothwell PE, Fuccillo MV, Maxeiner S, Hayton SJ, Gokce O, Lim BK, Fowler SC, Malenka RC, Südhof TC (2014) Autism-associated neuroligin-3 mutations commonly impair striatal circuits to boost repetitive behaviors. Cell 158:198-212.

Rumbaugh G, Adams JP, Kim JH, Huganir RL (2006) SynGAP regulates synaptic strength and mitogen-activated protein kinases in cultured neurons. Proc Natl Acad Sci USA 103:4344-4351.

Ryu HH, Lee YS (2016) Cell type-specific roles of RAS-MAPK signaling in learning and memory: implications in neurodevelopmental disorders. Neurobiol Learn Mem 135:13-21.
Sandweiss AJ, Brandt VL, Zoghbi HY (2020) Advances in understanding of Rett syndrome and MECP2 duplication syndrome: prospects for future therapies. Lancet Neurol 19:689-698.

Schreiber J, Grimbergen LA, Overwater I, Van Der Vaart T, Stedehouder J, Schuhmacher AJ, Guerra C, Kushner SA, Jaarsma $D$, Elgersma $Y$ (2017) Mechanisms underlying cognitive deficits in a mouse model for Costello syndrome are distinct from other RASopathy mouse models. Sci Rep 7:1256.

Seese RR, Maske AR, Lynch G, Gall CM (2014) Long-term memory deficits are associated with elevated synaptic ERK1/2 activation and reversed by mGluR5 antagonism in an animal model of autism. Neuropsychopharmacology 39:1664-1673.

Soong HK, Markham JA, Weiler IJ, Greenough WT (2008) Aberrant early-phase ERK inactivation impedes neuronal function in fragile X syndrome. Proc Natl Acad Sci USA 105:4429-4434.

Stornetta RL, Zhu JJ (2011) Ras and Rap signaling in synaptic plasticity and mental disorders. Neuroscientist 17:54-78.

Sztainberg Y, Zoghbi HY (2016) Lessons learned from studying syndromic autism spectrum disorders. Nat Neurosci 19:1408-1417.

Sztainberg Y, Chen HM, Swann JW, Hao S, Tang B, Wu Z, Tang J, Wan YW, Liu Z, Rigo F, Zoghbi HY (2015) Reversal of phenotypes in MECP2 duplication mice using genetic rescue or antisense oligonucleotides. Nature 528:123-126.

Tennant KA, Adkins DL, Donlan NA, Asay AL, Thomas N, Kleim JA, Jones TA (2011) The organization of the forelimb representation of the C57BL/6 mouse motor cortex as defined by intracortical microstimulation and cytoarchitecture. Cereb Cortex 21:865-876.

Van Woerden GM, Harris KD, Hojjati MR, Gustin RM, Qiu S, De Avila Freire R, Jiang YH, Elgersma Y, Weeber EJ (2007) Rescue of neurological deficits in a mouse model for Angelman syndrome by reduction of alphaCaMKII inhibitory phosphorylation. Nat Neurosci 10:280-282.

Vithayathil J, Pucilowska J, Landreth (2018) GE ERK/MAPK signaling and autism spectrum disorders. Prog Brain Res 241:63-112.

Wang X, Snape M, Klann E, Stone JG, Singh A, Petersen RB, Castellani RJ, Casadesus G, Smith MA, Zhu X (2012) Activation of the extracellular signal-regulated kinase pathway contributes to the behavioral deficit of fragile $x$-syndrome. J Neurochem 121:672-679.

Wen Y, Alshikho MJ, Herbert MR (2016) Pathway network analyses for autism reveal multisystem involvement, major overlaps with other diseases and convergence upon MAPK and calcium signaling. PLoS One 11:e0153329.

White FM, Wolf-Yadlin A (2016) Methods for the analysis of protein phosphorylation-mediated cellular signaling networks. Annu Rev Anal Chem (Palo Alto Calif) 9:295-315.

Yang G, Pan F, Gan WB (2009) Stably maintained dendritic spines are associated with lifelong memories. Nature 462:920-924.

Ye X, Carew TJ (2010) Small G protein signaling in neuronal plasticity and memory formation: the specific role of Ras family proteins. Neuron 68:340-361.

Zuo Y, Lin A, Chang P, Gan WB (2005) Development of long-term dendritic spine stability in diverse regions of cerebral cortex. Neuron 46:181-189. 